\title{
Effect of Levonorgestrel-Releasing Intrauterine System on Sexual and Urinary Functions
}

\author{
Arlıer S*, Uysal G, Seyfettinoğlu S, Nazik H, Kaya FO, Adıgüzel C, Yılmaz ES and Yücel O
}

Adana Numune Training and Research Hospital, Department of Obstetrics and Gynecology, Adana, Turkey

${ }^{*}$ Corresponding author: Arlier S, Adana Numune Training and Research Hospital, Department of Obstetrics and Gynecology, Adana, Turkey, Fax: +90 (322) 344 15 72, Tel: 905324861668, E-mail: sefaarlier@gmail.com

Citation: Arlıer S, Uysal G, Seyfettinoğlu S, Nazik H, Kaya FO, et al. (2017) Effect of Levonorgestrel-Releasing Intrauterine System on Sexual and Urinary Functions. J Gynecol Res 3(2): 202. doi: 10.15744/24543284.3.202

Received Date: August 23, 2017 Accepted Date: December 27, 2017 Published Date: December 29, 2017

\begin{abstract}
Aim: The effects of the levonorgestrel-intrauterine system (LNG-IUS) on urinary and sexual functions of women with idiopathic menorrhagia were evaluated using two internationally validated questionnaire forms.

Methods: This prospective study included (30-49) year-old women with idiopathic menorrhagia ( $\mathrm{n}=91$ ), who visited the Gynecology and Obstetrics Clinic of the hospital. The index of female sexual function (IFSF) questionnaire and the international consultation on incontinence modular questionnaire short form (ICIQ-UI) were used to evaluate sexual and urinary system functions, respectively, pre-, and 6 and 12 months post-LNG-IUS insertion.

Results: The IFSF scores were (mean \pm SD) $27.1 \pm 6.9,30.0 \pm 7.2$, and $32.7 \pm 7.5$ at pre-, and 6 and 12 months post-LNG-IUS insertion, respectively $(p<0.001)$. Compared with pre-LNG-IUS use among 91 patients, the IFSF score (symptoms improved) was increased in 47 and 60 patients and decreased (worsening symptoms) in 10 and 8 patients at 6 and 12 months post-LNG-IUS use, respectively. The ICIQ-UI scores were $4.9 \pm 4.4,3.7 \pm 4.0,2.8 \pm 3.0$ in pre-, 6 , and 12 months post-LNG-IUS insertion, respectively $(p<0.001)$. Compared with pre-LNG-IUS use, the ICIQ-UI score decreased (symptoms improved) in 33 women either in 6 or 12 months post-LNG-IUS use and increased (symptoms worsened) in 11 and 4 patients at 6 and 12 months post-LNG-IUS insertion, respectively.
\end{abstract}

Conclusion: A significant increase in the IFSF score and a marked decrease in the ICIQ-SF score because of LNG-IUS use in women with idiopathic menorrhagia indicate a noteworthy improvement in urinary and sexual functions.

Keywords: Levonorgestrel-Releasing Intrauterine System; Menorrhagia; Urinary Function; Sexual Function

\section{Introduction}

The levonorgestrel-intrauterine system (LNG-IUS; Mirena ${ }^{\circledR}$ Leiras Oy, Turku, Finland) has been used worldwide for various clinical indications, such as menorrhagia and dysmenorrhea, in addition to its common use as a contraceptive since it was first commercially introduced in 1990 [1]. Initially, 20- $\mu$ g levonorgestrel is released within 24 hours, while levonorgestrel release has been demonstrated to continue in a dose of higher than $14 \mu \mathrm{g}$ at the end of 5 years [2]. The efficacy of treatment is continuous by means of this regular release [3].

Menorrhagia and chronic pelvic pain negatively affect the quality of life as well as sexual and urinary functions of women [4-9]. In cases of unresponsiveness to medical treatment, radical elimination of abnormal uterine bleeding by hysterectomy may worsen sexual and urinary functions. In addition to an increased risk of morbidity and mortality, damage to the innervation of the pelvic region may cause further health issues [10]. The LNG-IUS is an effective, reliable, reversible and relatively less invasive low cost therapy to treat menorrhagia, endometrial hyperplasia, and dysmenorrhea [11].

By evaluating the effects of abnormal uterine bleeding, pelvic pain, and pressure on sexual functions, Mathias et al. [12] established menorrhagia and pelvic organ prolapse [13] as one of the most important underlying factors affecting sexual functions. Similarly, abnormal uterine bleeding was similarly proven to negatively affect the quality of life of women $[14,15]$.

The literature contains a few studies that have evaluated the effect of LNG-IUS use on either urinary or sexual functions in patients with menorrhagia [16-19]. However, this is the first study to evaluate both urinary functions and sexual life by using two internationally validated standard questionnaires to objectively establish the effects of LNG-IUS use on urinary and sexual functions of women with menorrhagia. 


\section{Materials and Methods}

This prospective study was performed on patients who presented with menorrhagia between June 1,2014 and October 1, 2015 at the Department of the Gynecology and Obstetrics Clinic of the Health University Adana Numune Education and Training Hospital in Turkey; the hospital's ethics board approved this study. A detailed explanation of the study and information about the application of LNG-IUS were provided to each participant, and both written and verbal consent was obtained. Initially, endometrial biopsy was performed on the patients to evaluate the etiology of menorrhagia. Following the evaluation of the pathology reports, LNGIUS was applied to patients with abnormal uterine bleeding. This study included 91 women in the age range 30-49 years who were experiencing idiopathic menorrhagia according to clinical and pathological findings. A total of 94 patients were excluded from the study, including those planning to become pregnant (26 patients) or those with space-occupying lesions in the uterine cavity, such as endometrial polyp (12 patients), leiomyoma ( 9 patients), endometritis ( 7 patients), a malignant pathology (4 patients), simple atypical hyperplasia (3 patients) or complex atypical hyperplasia (2 patients) as detected by endometrial biopsy, or sexually transmitted diseases (8 patients), such as chlamydia or gonorrhea related pelvic inflammatory disease (PID), or abnormal PAP smear result (6 patients) or cases with pelvic organ prolapses (4 patients) or a history of either thromboembolism ( 1 patient) or stroke or coronary heart disease (1 patient), or cardiac valve replacement and chronic use of thrombolytic drugs ( 2 patients) or any type of cancer (2 patients) or migraines (4 patients).

Patients in the study groups were questioned about age, duration of marriage, level of education, number of births, and status of menstruation and the results were recorded. Body mass index (BMI) was calculated by measuring the patients' height and weight. The index of female sexual function (IFSF) form was used to evaluate sexual functions prior to the application. All women included in the study were asked to read and answer the IFSF questions, which included nine items, on their own. A female resident physician assisted illiterate women. This domestically and internationally validated form was used to evaluate sexual function with a minimum of five and a maximum of 45 points. IFSF was used to assess sexual function of the patient. Linguistic validation of this questionnaire was conducted in Turkey [20]. The specific questions analyzed in the IFSF included quality of sexual intercourse (questions 1 and 2; possible total score, 0 to 10), desire (questions 4 and 5; possible total score, 2 to 10), overall satisfaction with sexual function (questions 6 and 7; possible total score, 2 to 10), ability to achieve orgasm (question 8; possible total score, 1 to 5), the degree of lubrication (question 2; possible total score, 0 to 5), and the degree of clitoral sensation (question 9; possible total score, 1 to 5 ). The responses were graded on a scale of 1 (almost never or never) to 5 (almost always or always). A score of 0 indicated no attempt at intercourse. The total scores range from 5 to 45 with lower scores representing poorer sexual function. Urinary problems were evaluated with the standard international consultation on incontinence modular questionnaire short form (ICIQ-UI), which was previously validated both domestically and internationally with a minimum of 0 and a maximum of 20 points [21]. This form questions the frequency and amount of urinary incontinence; the effects of this problem on daily life; and whether the urinary incontinence is stress, urge, mixed or not.

General systemic and gynecological examinations of all patients included in the study were performed. Bimanual genital examination and transvaginal-ultrasonography (TV-USG; Mindray, DC-7 Nanshan Shenzhen P.R. China 5-7 MHz vaginal probe) was applied to all patients prior to LNG-IUS application. A vaginal speculum was inserted prior to the application of LNG-IUS, the cervix and vagina were cleaned, and the anterior cervix was held by a single-tooth tenaculum. The LNG-IUS was placed into the endometrial cavity using the standard method without anesthesia. After the application, TV-USG was used to determine if the device was placed correctly. At the end of both 6 and 12 months, the status of bleeding, any side effects, or any additional problems observed were recorded. The urinary and sexual functions of the patients were re-evaluated 6 and 12 months after the LNG-IUS application. The total IFSF and ICIQ-UI short form scores of women were calculated and compared for both time periods.

Student's t-test was used to analyze parametric data to determine the difference between the two independent groups, and a paired t-test was used to determine differences between two dependent groups. ANOVA was used to compare differences between more than two independent groups followed by a Tukey post-hoc test. Repeated measures ANOVA were used to compare differences between more than two dependent groups. The Friedman test was used to compare the ranks of more than two dependent groups for the analysis of nonparametric data. Frequency and percentage were used to describe categorical data. A $p$ value $<0.05$ was accepted as significant. MedCalc and SPSS software were used in the analyses.

\section{Results}

The LNG-IUS was applied to 91 patients appropriate the study inclusion criteria and with benign pathology results. The mean age of the patients was 42.6 years (range from 30 to 49). The mean number of births and BMI was 3.4 (range from 0 to 8 ) and 27.6 $\mathrm{kg} / \mathrm{m}^{2}$ (range from 21.3 to 40.1 ), respectively. No complications occurred in any patient during the LNG-IUS insertion (Table 1).

The level of education among the subjects was low (79\% at the level of middle school or under). More than $92 \%$ of the patients were unemployed with the majority being housewives (Table 2).

Eighty-two patients (90.1\%) preferred to continue the system 6 months after insertion and 77 patients (84.6\%) preferred to continue using the system 12 months after insertion. Hypomenorrhea, hypermenorrhea, spotting, and amenorrhea were observed in $50(64.8 \%), 6(6.6 \%), 9(9.9 \%)$ and $17(18.7 \%)$ patients at 6 months and $48(52.7 \%), 0(0 \%), 13(14.3 \%)$, and $20(22.0 \%)$ at 12 months after insertion, respectively (Table 3 ). 


\begin{tabular}{|c|c|c|c|c|c|}
\hline & N & Min. & Max. & Mean & SD \\
\hline Age (year) & 91 & 30 & 49 & 42.6 & 4.7 \\
\hline Parity & 91 & 0 & 8 & 3.6 & 1.6 \\
\hline $\begin{array}{c}\text { Duration after the last } \\
\text { birth (year) }\end{array}$ & 87 & 1 & 26 & 12.1 & 5.9 \\
\hline BMI & 91 & 20.7 & 40.1 & 26.9 & 3.6 \\
\hline
\end{tabular}

Min: Minimum; Max: Maximum; SD: Standard Deviation; BMI: Body Mass Index

Table 1: Distribution of patients according to age, number of births, duration after the last delivery, and BMI

\begin{tabular}{|c|c|c|c|}
\hline \multirow{4}{*}{$\begin{array}{c}\text { Status of } \\
\text { Employment }\end{array}$} & Frequency & Percentage \\
\cline { 2 - 4 } & Unemployed & 7 & 7.7 \\
\hline \multirow{5}{*}{ Level of education } & Illiterate & 5 & 92.3 \\
\cline { 2 - 4 } & $\begin{array}{c}\text { Literate } \\
\text { Primary school } \\
\text { graduate }\end{array}$ & 12 & 5.5 \\
\cline { 2 - 4 } & $\begin{array}{c}\text { High school } \\
\text { graduate }\end{array}$ & 55 & 13.2 \\
\cline { 2 - 4 } & $\begin{array}{c}\text { University } \\
\text { graduate }\end{array}$ & 14 & 60.4 \\
\hline \multirow{5}{*}{ Systemic disease } & DM & 10 & 5.5 \\
\cline { 2 - 5 } & Hypertension & 12 & 11.0 \\
\cline { 2 - 5 } & $\begin{array}{c}\text { Thyroid } \\
\text { disease }\end{array}$ & 13 & 13.2 \\
\cline { 2 - 5 } & None & 56 & 61.5 \\
\hline
\end{tabular}

DM: Diabetes Mellitus

Table 2: Classification of patients according to the level of education, type of employment, and presence of systemic diseases

\begin{tabular}{|c|c|c|c|}
\hline Pain & $\begin{array}{c}\text { Pre-LNG-IUS } \\
\text { N (\%) }\end{array}$ & $\begin{array}{c}6 \text { months later } \\
N(\%)\end{array}$ & $\begin{array}{c}12 \text { months later } \\
\mathrm{N}(\%)\end{array}$ \\
\hline Yes & $44(48.3)$ & & \\
\hline No & $47(51.7)$ & $49(53.8)$ & $55(60.4)$ \\
\hline Pain increase & & $8(8.7)$ & $6(6.5)$ \\
\hline Pain decrease & & $15(16.4)$ & $13(14.2)$ \\
\hline No change & & $10(10.9)$ & $7(7.6)$ \\
\hline Discontinuation & & $9(9.8)$ & $10(10.9)$ \\
\hline \multicolumn{4}{|c|}{ Bleeding pattern } \\
\hline Hypomenorrhea & 0 & $50(64.8)$ & $48(52.7)$ \\
\hline Hypermenorrhea & 91 & $6(6.6)$ & $0(0)$ \\
\hline Spotting & 0 & $9(9.9)$ & $13(14.3)$ \\
\hline Amenorrhea & 0 & $17(18.7)$ & $20(22.0)$ \\
\hline Discontinuation & 0 & $9(9.9)$ & $10(11.0)$ \\
\hline \multicolumn{4}{|c|}{ Incontinence status } \\
\hline No incontinence & 35 & 31 & 27 \\
\hline Urge incontinence & 3 & 3 & 4 \\
\hline Stress incontinence & 21 & 36 & 33 \\
\hline Mix incontinence & 32 & 14 & 13 \\
\hline Discontinuation & 0 & 9 & 10 \\
\hline
\end{tabular}

Table 3: Clinical features before, and 6 months and 12 months after LNG-IUS therapy

The sexual questionnaire score increased in 47 patients (74.6\%), decreased in ten patients (12.7\%), and was unchanged in 10 patients (12.7\%). Eight patients did not answer the sexual questionnaire score at the time of pre-LNG-IUS insertion due to taboo status or cultural reasons. An additional 4 and 7 subjects were not included in the sexual questionnaire score because the LNG-IUS slipped out of the uterine cavity or voluntary termination of LNG-IUS use as well as undergoing surgical procedures at the end of 6 months and 12 months after insertion, respectively. In addition, 64 patients (70.3\%) and 65 patients (71.4\%) reported that both 
urinary and sexual symptoms improved according to the questionnaire score at the end of 6 months and 12 months after insertion, respectively. In contrast, 7 patients (8.5\%) reported worsening in both urinary and sexual symptoms at the end of 6 and 12 months. The mean ICIQ-UI short form score at baseline (pre-LNG-IUS insertion) was 4.9 \pm 4.4 (mean \pm SD) which significantly reduced to $3.7 \pm 4.0$ at the end of 6 months $(\mathrm{p}<0.005)$ and reduced further to $2.8 \pm 3.0$ at the end of 12 months after insertion ( $<<0.005)$. Mean IFSF score prior to the LNG-IUS application was 27.1 \pm 6.9 . Mean sexual function score was lowest $(23.0 \pm 4.3)$ in women with heavy uterine bleeding and mixed urinary incontinence $(\mathrm{p}<0.005)$ and increased to $30.0 \pm 7.2$, and to $32.7 \pm 7.5$, 6 months and 12 months post-LNG-IUS insertion, respectively $(\mathrm{p}<0.005)$. A further 2.7 increase in mean IFSF score was significant at 12 months postLNG-IUS insertion vs. 6 months post-LNG-IUS insertion ( $\mathrm{p}<0.005$; Table $4 \mathrm{a}$ and $\mathrm{b})$.

\begin{tabular}{|c|c|c|c|c|c|c|}
\hline & \multicolumn{3}{|c|}{ IFSF score } & \multicolumn{3}{c|}{ ICIQ-UI score } \\
\hline & Pre-LNG-IUS & \multicolumn{2}{|c|}{ Post-LNG-IUS } & Pre-LNG-IUS & \multicolumn{2}{c|}{ Post-LNG-IUS } \\
\hline N & & $\mathbf{6}$ mo. & $\mathbf{1 2}$ mo. & & $\mathbf{6}$ mo. & 12 mo. \\
\hline Min. & 83 & 79 & 72 & 91 & 82 & 77 \\
\hline Max. & 5 & 5 & 5 & 0 & 0 & 0 \\
\hline Mean & 27.1 & 34 & 44 & 14 & 14 & 12 \\
\hline SD & 6.9 & 7.2 & 7.5 & 4.9 & $3.7^{*}$ & $2.8^{*}$ \\
\hline
\end{tabular}

Min.: Minimum; Max.: Maximum; SD: Standard Deviation; Mo.: Months ${ }^{*} p<0.005$ vs. pre-LNG-IUS. ${ }^{\psi} p<0.005$ vs. 6 months post-LNG-IUS

Table 4a: IFSF and ICIQ-UI scores before (pre-) and 6 or 12 months after (post-) LNG-IUS insertion

\begin{tabular}{|c|c|c|c|c|}
\hline & & N & Correlation & $P$ \\
\hline Pair 1 & $\begin{array}{c}\text { IFSF score 0 \& } \\
\text { IFSF score 6 }\end{array}$ & 79 & 0.795 & 0.005 \\
\hline Pair 2 & $\begin{array}{c}\text { IFSF score 0 \& } \\
\text { IFSF score 12 }\end{array}$ & 72 & 0.734 & 0.005 \\
\hline Pair 3 & $\begin{array}{c}\text { IFSF score 6 \& } \\
\text { IFSF score 12 }\end{array}$ & 72 & 0.937 & 0.005 \\
\hline Pair 4 & $\begin{array}{c}\text { ICIQ-UI score 0 \& } \\
\text { ICIQ-UI score 6 }\end{array}$ & 82 & 0.718 & 0.005 \\
\hline Pair 5 & $\begin{array}{c}\text { ICIQ-UI score 0 \& } \\
\text { ICIQ-UI score 12 }\end{array}$ & 77 & 0.677 & 0.005 \\
\hline Pair 6 & $\begin{array}{c}\text { ICIQ-UI score 6 \& } \\
\text { ICIQ-UI score 12 }\end{array}$ & 77 & 0.889 & 0.005 \\
\hline
\end{tabular}

Table 4b: Paired Samples Correlations

\section{Discussion}

Menorrhagia is a commonly encountered problem affecting the quality of life of women of reproductive age and especially during the premenopausal period [22,23] with negative physical, social, and emotional consequences resulting in withdrawal from daily life $[6,24]$ and the sexual life of women $[15,22,24]$. LNG-IUS is a widely preferred application with proven efficacy and reliability in contraception and in the treatment of menorrhagia in 120 countries worldwide $[25,26]$. In a study in which mean satisfaction was evaluated in women using LNG-IUS, 95\% women were satisfied with this system and 99\% women selected the same method at the end of 5 years [27]. Several other studies also reported improvement in sexual functions in women using LNG-IUS [8,28,29]. In addition to this beneficial effect, additional positive effects of LNG-IUS use on patient satisfaction and quality of life have been reported because it decreases the amount of bleeding and the pelvic sensation of pain [30-33] and also helps to reduce dysmenorrhea and provide relief from premenstrual stress symptoms due to the progestogenic effect of levonorgestrel $[4,7,34,35]$. Moreover, LNG-IUS has positive effects on urinary functions [19,36,37].

Positive correlation between these two scorers was observed at both 6 and 12 months.

LNG-IUS delivers low plasma levonorgestrel and results in minimal side effects. The occurrence of a systemic disease, such as DM or HT, suggests the use of LNG-IUS [38,39]. This study population experienced a higher rate of DM, HT, and thyroid diseases.

The socio-cultural context is the most important factor when determining the method to be applied to women and the type of treatment method that should be performed [40]. The choice of LNG-IUS is influenced by larger social factors, economic status, education level, and both individual and interpersonal experience [41-43]. Previous studies have also indicated that the sociocultural context influences the experience of menorrhagia, particularly with regard to sexuality and LNG-IUS preferences [41-43]. The current study population had low socio-economic and low education levels. Working status was also associated with some aspects of LNG-IUS use; the current study population was generally midwives. Women working outside the home or those in formal employment also used modern contraception methods more than those in self-employment or the unemployed [44]. Low- 
Journal of Gynecology Research

income women preferred LNG-IUD, which provides LNG-IUS through general health insurance. Our results show that women who reported abnormal uterine bleeding preferred to use LNG-IUS among unemployed housewives and women with a low level of education.

A previous study has reported that in $58.6 \%$ women using LNG-IUS, no serious complications were noted at the end of 12 months [45]. However, spotting was observed in $17.1 \%$ patients, heavy bleeding in $1.4 \%$, and amenorrhea in $22.9 \%$ which increased to $27.5 \%$ at the end of 18 months [45]. However, at the end of 12 months, the rates of amenorrhea (22\%) and spotting (14.3\%) observed in the current study were much lower than those reported in previous studies.

Following application, the LNG-IUS may drop from the uterine cavity or some patients may request the removal of the system due to dissatisfaction for various reasons [46]. In the present study, the rate of continuation of LNG-IUS use was $90.2 \%$ at the end of 6 months and $84.6 \%$ at the end of 12 months. This rate was reported as $74 \%$ at the end of an 18 -month follow-up by a previous study assessing the efficacy of LNG-IUS to prevent heavy menstrual bleeding [45], and 93\% at the end of a follow-up of 12 months in another study assessing LNG-IUS-related contraceptive experience and levels of satisfaction [47]. Moreover, in a recent contraceptive-related study, satisfaction (85.2\%) and continuation (78.6\%) of LNG-IUS use was reported at the end of a follow-up of 6 months, including expulsions (3 patients, 2.7\%) and removals (20 patients, 18.75\%) [48]. These results suggest that the medical reasons for LNG-IUS use may significantly affect continuation and satisfaction rates.

Heliovaara et al. [49] compared two groups of patients (117 who underwent hysterectomy and 119 who received LNG-IUS) and found that urinary tract infections, dysuria, decrease in the daily frequency of urination, and lower urinary tract symptoms significantly improved in the group with LNG-IUS application at the end of 6 months. On the other hand, the mean ICIQ-UI short form score was higher in the current study compared with previously published results [50]. Although the purpose of using LNGIUS was different in the current study, the evaluation of 160 patients in the age range 20-35 years using LNG-IUS versus a copper IUD revealed significantly increased scores for the SF36 questionnaire at the end of 6 months with regard to physical function, general health, social function, emotional role, life energy, and mental health [51]. Studies performed to establish both the effects and treatment of abnormal uterine bleeding on the quality of life showed that women preferred the use of LNG-IUS to hysterectomy and found that the use of LNG-IUS improved the quality of life of women [27,52]. In addition, studies of premenstrual syndrome (PMS) also showed that LNG-IUS use improved sexual functions in this patient population $[4,8,28]$.

Similar to the findings in prior studies [10,27,53], the use of the IFSF score in the present study detected improved sexual functions of patients with idiopathic menstrual bleeding 6 and 12 months post-LNG-IUS insertion vs pre-LNG-IUS insertion. In a previous study performed in Italy [4], the mean IFSF score in patients using LNG-IUS was 30.1 at baseline and 32.0 at the end of 12 months with no statistically significant difference in the sexual function score. These scores stated above were higher than the scores in the present study. However, they reported a significant improvement in sexual desire and a decreased sensation of pain during sexual intercourse at the end of 12 months.

The patients were evaluated using a visual analog scale (VAS) in one study performed on 66 premenopausal women with an age range of 26-55 years. This questionnaire included questions related to pelvic pain, sexual life (libido), and a general feeling of health. The baseline score of pelvic pain (4.32) decreased significantly to 3.55 at the end of 6 months. Scores of libido and a general feeling of health were 4.27-4.95 and 3.47-6.87 at baseline and at the end of 6 months, respectively. The general quality of life score was significantly increased from 3.47 to 6.87 before and after the insertion of LNG-IUS, respectively. In that study, the level of libido, sensation of pain, and general well-being of women notably improved at the end of 6 months after LNG-IUS application [34]. In a previous study that compared LNG-IUS versus other copper-containing IUDs, quality of life scales such as energetic self-sensation, emotional well-being, and sexual desire and libido scores were significantly higher in individuals using LNG-IUS [29]. In contrast, other studies have reported unchanged or slightly decreased scores (2\%) of Brief Index of Sexual Functioning for Women (BISF-W) and Arizona Sexual Experiences Scale (ASEX) that were used to evaluate sexual desire [54]. Additionally, parallel to that study, another study reported that LNG-IUS application resulted in a decrease in sexual functions and sexual desire (35.1\% of patients) [55].

LNG-IUS use effectively decreases pain and improves quality of life in women experiencing heavy menstrual bleeding and dysmenorrhea $[30,32,56,57]$. In several clinical conditions, chronic pelvic pain may occur in the form of dysmenorrhea, dyspareunia, continuous or intermittent pelvic pain, and pain on micturition. During reproductive life, particularly premenopausal period $40 \%$ to $95 \%$ of all women encounter such problems [52,57]. Following LNG-IUS insertion, LNG release elicits local effects on the endometrium and other layers of the uterus. However, minimal passage of LNG to the systemic circulation decreases the sensation of pain and discomfort on genital and other pelvic organs, lessens endometrial bleeding [58] and reduces blood flow to the uterus and endometrium and thus, decreases pelvic congestion, bleeding, and pelvic pain [59,60]. Our results further support the beneficial effects of LNG-IUS on urinary functions. The result may be a markedly greater beneficial effect for those using LNGIUS with baseline low IFSF scores

\section{Conclusion}

In conclusion, in the present study, LNG-IUS use in women with menorrhagia had positive effects on urinary and sexual functions compared to baseline, showed a significant increase in IFSF score, and a significant decrease in the ICIQ-SF score compared to 
pre-LNG-IUS insertion. In addition, changes in urinary and sexual symptoms compared to pre-LNG-IUS use showed a positive correlation and urge incontinence symptoms in patients with mixed urinary incontinence was significantly reduced. The LNG-IUS may be used in women with idiopathic menorrhagia and may have good acceptance and tolerance.

\section{Reference}

1. Nilsson CG, Luukkainen T, Diaz J, Allonen H (1981) Intrauterine contraception with levonorgestrel: a comparative randomised clinical performance study. Lancet 1: $577-80$.

2. Vercellini P, Vigano P, Somigliana E (2005) The role of the levonorgestrel-releasing intrauterine device in the management of symptomatic endometriosis. Curr Opin Obstet Gynecol 17: 359-65.

3. Sivin I, Stern J, Coutinho E, Mattos CE, el Mahgoub S, et al. (1991) Prolonged intrauterine contraception: a seven-year randomized study of the levonorgestrel $20 \mathrm{mcg} /$ day (LNg 20) and the Copper T380 Ag IUDS. Contraception 44: 473-80.

4. Bastianelli C, Farris M, Benagiano G (2011) Use of the levonorgestrel-releasing intrauterine system, quality of life and sexuality. Experience in an Italian family planning center. Contraception 84: 402-8.

5. Bayoglu Tekin Y, Dilbaz B, Altinbas SK, Dilbaz S (2011) Postoperative medical treatment of chronic pelvic pain related to severe endometriosis: levonorgestrelreleasing intrauterine system versus gonadotropin-releasing hormone analogue. Fertil Steril 95: 492-6.

6. Karlsson TS, Marions LB, Edlund MG (2014) Heavy menstrual bleeding significantly affects quality of life. Acta Obstet Gynecol Scand 93: 52-7.

7. Takeda T, Kondo A, Koga S, Hayakawa J, Hayakawa K, et al. (2015) Effectiveness of ethinylestradiol/drospirenone for premenstrual symptoms in Japanese patients with dysmenorrhea: Open-label pilot study. J Obstet Gynaecol Res 41: 1584-90.

8. Kiykac Altinbas S, Bayoglu Tekin Y, Dilbaz B, Dilbaz S (2015) Evaluation of quality of life in fertile Turkish women with severe endometriosis. J Obstet Gynaecol 35: 49-52.

9. Pirimoglu ZM, Ozyapi AG, Kars B, Buyukbayrak EE, Solak Y, et al. (2011) Comparing the effects of intrauterine progestin system and oral progestin on healthrelated quality of life and Kupperman index in hormone replacement therapy. J Obstet Gynaecol Res 37: 1376-81.

10. Halmesmaki K, Hurskainen R, Teperi J, Grenman S, Kivelä A, et al. (2007) The effect of hysterectomy or levonorgestrel-releasing intrauterine system on sexual functioning among women with menorrhagia: a 5-year randomised controlled trial. BJOG 114: 563-8.

11. Lahteenmaki P, Haukkamaa M, Puolakka J, Riikonen U, Sainio S, et al. (1998) Open randomised study of use of levonorgestrel releasing intrauterine system as alternative to hysterectomy. BMJ 316: 1122-6.

12. Mathias SD, Kuppermann M, Liberman RF, Lipschutz RC, Steege JF (1669) Chronic pelvic pain: prevalence, health-related quality of life, and economic correlates. Obstet Gynecol 87: 321-7.

13. Al-Badr A (2013) Quality of Life Questionnaires for the Assessment of Pelvic Organ Prolapse: Use in Clinical Practice. Low Urin Tract Symptoms 5: 121-8.

14. Gokyildiz S, Aslan E, Beji NK, Mecdi M (2013) The Effects of Menorrhagia on Women’s Quality of Life: A Case-Control Study. ISRN Obstet Gynecol 2013: doi: $10.1155 / 2013 / 918179$

15. Lukes AS, Baker J, Eder S, Adomako TL (2012) Daily menstrual blood loss and quality of life in women with heavy menstrual bleeding. Womens Health (Lond Engl) 8: 503-11.

16. Kovalevsky G, Ballagh SA, Stanczyk FZ, Lee J, Cooper J, et al. (2010) Levonorgestrel effects on serum androgens, sex hormone-binding globulin levels, hair shaft diameter, and sexual function. Fertil Steril 93: 1997-2003.

17. Kocaoz S, Talas MS, Atabekoglu CS (2012) Urinary incontinence among Turkish women: an outpatient study of prevalence, risk factors, and quality of life. J Wound Ostomy Continence Nurs 39: 431-9.

18. Hurskainen R, Teperi J, Rissanen P, Aalto AM, Grenman S, et al. (2001) Quality of life and cost-effectiveness of levonorgestrel-releasing intrauterine system versus hysterectomy for treatment of menorrhagia: a randomised trial. Lancet 357: 273-7.

19. Ekin M, Cengiz H, Ayag ME, Kaya C, Yasar L, et al. (2013) Effects of the levonorgestrel-releasing intrauterine system on urinary symptoms in patients with adenomyosis. Eur J Obstet Gynecol Reprod Biol 170: 517-20.

20. Kaplan SA, Reis RB, Kohn IJ, Ikeguchi EF, Laor E, et al. (1999) Safety and efficacy of sildenafil in postmenopausal women with sexual dysfunction. Urology 53: $481-6$.

21. Cetinel B, Ozkan B, Can G (2004) The validation study of ICIQ-SF Turkish version. Turk J Urol 30: 332-8.

22. Clark TJ, Khan KS, Foon R, Pattison H, Bryan S, et al. (2002) Quality of life instruments in studies of menorrhagia: a systematic review. Eur J Obstet Gynecol Reprod Biol 104: 96-104.

23. Jenkinson C, Peto V, Coulter A (1994) Measuring change over time: a comparison of results from a global single item of health status and the multi-dimensional SF-36 health status survey questionnaire in patients presenting with menorrhagia. Qual Life Res 3:317-21.

24. Bushnell DM, Martin ML, Moore KA, Richter HE, Rubin A, et al. (2010) Menorrhagia Impact Questionnaire: assessing the influence of heavy menstrual bleeding on quality of life. Curr Med Res Opin 26: 2745-55.

25. Blumenthal PD, Trussell J, Singh RH, Guo A, Borenstein J, et al. (2006) Cost-effectiveness of treatments for dysfunctional uterine bleeding in women who need contraception. Contraception 74: 249-58.

26. Jensen JT (2005) Contraceptive and therapeutic effects of the levonorgestrel intrauterine system: an overview. Obstet Gynecol Surv 60: 604-12.

27. Lete I, Obispo C, Izaguirre F, Orte T, Rivero B, et al. (2008) The levonorgestrel intrauterine system (Mirena) for treatment of idiopathic menorrhagia. Assessment of quality of life and satisfaction. Eur J Contracept Reprod Health Care 13: 231-7.

28. Heliovaara-Peippo S, Hurskainen R, Teperi J, Aalto AM, Grénman S, et al. (2013) Quality of life and costs of levonorgestrel-releasing intrauterine system or hysterectomy in the treatment of menorrhagia: a 10-year randomized controlled trial. Am J Obstet Gynecol 209: 535.e1-535.e14.

29. Skrzypulec V, Drosdzol A (2008) Evaluation of quality of life and sexual functioning of women using levonorgestrel-releasing intrauterine contraceptive system-Mirena. Coll Antropol 32: 1059-68.

30. Ji F, Yang XH, Ai Xing Zi AL, Ha Ni Ke Zi TX, He Y, et al. (2014) Role of levonorgestrel-releasing intrauterine system in dysmenorrhea due to adenomyosis and the influence on ovarian function. Clin Exp Obstet Gynecol 41: 677-80.

31. Hickey M, Krikun G, Kodaman P, Schatz F, Carati C, et al. (2006) Long-term progestin-only contraceptives result in reduced endometrial blood flow and oxidative stress. The Journal of clinical endocrinology and metabolism 91: 3633-8. 
32. Cihangir U, Ebru A, Murat E, Levent Y (2013) Mechanism of action of the levonorgestrel-releasing intrauterine system in the treatment of heavy menstrual bleeding. Int J Gynaecol Obstet 123: 146-9.

33. Bastianelli C, Farris M, Rapiti S, Vecchio RB, Benagiano G (2014) Different bleeding patterns with the use of levonorgestrel intrauterine system: are they associated with changes in uterine artery blood flow? BioMed Res Int 2014: 815127.

34. Gorgen H, Api M, Akca A, Cetin A (2009) Use of the Levonorgestrel-IUS in the treatment of menorrhagia: assessment of quality of life in Turkish users. Arch Gynecol Obstet 279: 835-40.

35. Hurskainen R, Paavonen J, Teperi J (2003) The effectiveness of the levonorgestrel-releasing intrauterine system in menorrhagia: a systematic review. BJOG 110: 87-8.

36. Sotnikova N, Antsiferova I, Malyshkina A (2002) Cytokine network of eutopic and ectopic endometrium in women with adenomyosis. Am J Reprod Immunol 47: 251-5.

37. Ulukus EC, Ulukus M, Seval Y, Zheng W, Arici A (2005) Expression of interleukin-8 and monocyte chemotactic protein-1 in adenomyosis. Hum Reprod 20: 2958-63.

38. Kiley JW, Hammond C, Niznik C, Rademaker A, Liu D, et al. (2015) Postpartum glucose tolerance in women with gestational diabetes using levonorgestrel intrauterine contraception. Contraception 91: 67-70.

39. Long ME, Faubion SS, MacLaughlin KL, Pruthi S, Casey PM (2015) Contraception and hormonal management in the perimenopause. J Womens Health (Larchmt) 24: 3-10.

40. Van der Velden T, Ping C (2002) The introduction of Norplant in Cambodia through the private sector. Asia Pac J Public Health 14: 69-74.

41. Iseyemi A, Zhao Q, McNicholas C, Peipert JF (2017) Socioeconomic Status As a Risk Factor for Unintended Pregnancy in the Contraceptive CHOICE Project. Obstet Gynecol 130: 609-15.

42. Dehlendorf C, Anderson N, Vittinghoff E, Grumbach K, Levy K, et al. (2017) Quality and Content of Patient-Provider Communication About Contraception: Differences by Race/Ethnicity and Socioeconomic Status. Womens Health Issues 27: 530-8.

43. McMillan K, Worth H (2011) The impact of socio-cultural context on young people's condom use: evidence from two Pacific Island countries. Cult Health Sex 13: 313-26.

44. Ochako R, Izugbara C, Okal J, Askew I, Temmerman M (2016) Contraceptive method choice among women in slum and non-slum communities in Nairobi, Kenya. BMC Womens Health 16: 35.

45. Mansukhani N, Unni J, Dua M, Darbari R, Malik S, et al. (2013) Are women satisfied when using levonorgestrel-releasing intrauterine system for treatment of abnormal uterine bleeding? J Midlife Health 4: 31-5.

46. Kuzel D, Hrazdirova L, Kubinova K, Dundr P, Cibula D, et al. (2013) Hysteroscopic management of displaced levonorgestrel-releasing intrauterine system. J Obstet Gynaecol Res 39: 1014-8.

47. Zhao S, Deng J, Wang Y, Bi S, Wang X, et al. (2014) Experience and levels of satisfaction with the levonorgestrel-releasing intrauterine system in China: a prospective multicenter survey. Patient Prefer Adherence 8: 1449-55.

48. Flamant A, Ouldamer L, Body G, Trignol-Viguier N (2013) Rates of continuation and satisfaction of immediate intrauterine device insertion following first- or second-trimester surgical abortion: a French prospective cohort study. Eur J Obstet Gynecol Reprod Biol 169: 268-74.

49. Heliovaara-Peippo S, Halmesmaki K, Hurskainen R, Teperi J, Grenman S, et al. (2010) The effect of hysterectomy or levonorgestrel-releasing intrauterine system on lower urinary tract symptoms: a 10-year follow-up study of a randomised trial. BJOG 117: 602-9.

50. Ramazanzadeh F, Tavakolianfar T, Shariat M, Purafzali Firuzabadi SJ, Hagholahi F (2012) Levonorgestrel-releasing IUD versus copper IUD in control of dysmenorrhea, satisfaction and quality of life in women using IUD. Iran J Reprod Med 10: 41-6.

51. Alhamdan D, Bignardi T, Hardas G, Merkur H, Condous G (2010) Mirena intra-uterine system: does it improve long term symptoms in women with chronic pelvic pain and/or endometriosis after laparoscopy? A multicentre randomized controlled trial. Rev Recent Clin Trials 5: 143-6.

52. Gemzell-Danielsson K, Inki P, Boubli L, O’Flynn M, Kunz M, et al. (2010) Bleeding pattern and safety of consecutive use of the levonorgestrel-releasing intrauterine system (LNG-IUS)--a multicentre prospective study. Hum Reprod 25: 354-9.

53. McGahuey CA, Gelenberg AJ, Laukes CA, Moreno FA, Delgado PL, et al. (2000) The Arizona Sexual Experience Scale (ASEX): reliability and validity. J Sex Marital Ther 26: 25-40.

54. Enzlin P, Weyers S, Janssens D, Poppe W, Eelen C, et al. (2012) Sexual functioning in women using levonorgestrel-releasing intrauterine systems as compared to copper intrauterine devices. J Sex Med 9: 1065-73.

55. Imai A, Matsunami K, Takagi H, Ichigo S (2014) Levonorgestrel-releasing intrauterine device used for dysmenorrhea: five-year literature review. Clin Exp Obstet Gynecol 41: 495-8.

56. Deng S, Lang JH, Leng JH, Liu ZF, Sun DW, et al. (2006) Effects of levonorgestrel-releasing intrauterine system on pain and recurrence associated with endometriosis and adenomyosis. Zhonghua Fu Chan Ke Za Zhi 41: 664-8.

57. Matorras R, Ballesteros A, Prieto B, Ocerin I, Expósito A, et al. (2011) Efficacy of the levonorgestrel-releasing intrauterine device in the treatment of recurrent pelvic pain in multitreated endometriosis. J Reprod Med 56: 497-503.

58. Koh SC, Singh K (2007) The effect of levonorgestrel-releasing intrauterine system use on menstrual blood loss and the hemostatic, fibrinolytic/inhibitor systems in women with menorrhagia. J Thromb Haemost 5: 133-8.

59. Lockhat FB, Emembolu JO, Konje JC (2005) The efficacy, side-effects and continuation rates in women with symptomatic endometriosis undergoing treatment with an intra-uterine administered progestogen (levonorgestrel): a 3 year follow-up. Hum Reprod 20: 789-93.

60. Abou-Setta AM, Houston B, Al-Inany HG, Farquhar C (2013) Levonorgestrel-releasing intrauterine device (LNG-IUD) for symptomatic endometriosis following surgery. Cochrane Database Syst Rev 1: CD005072. 


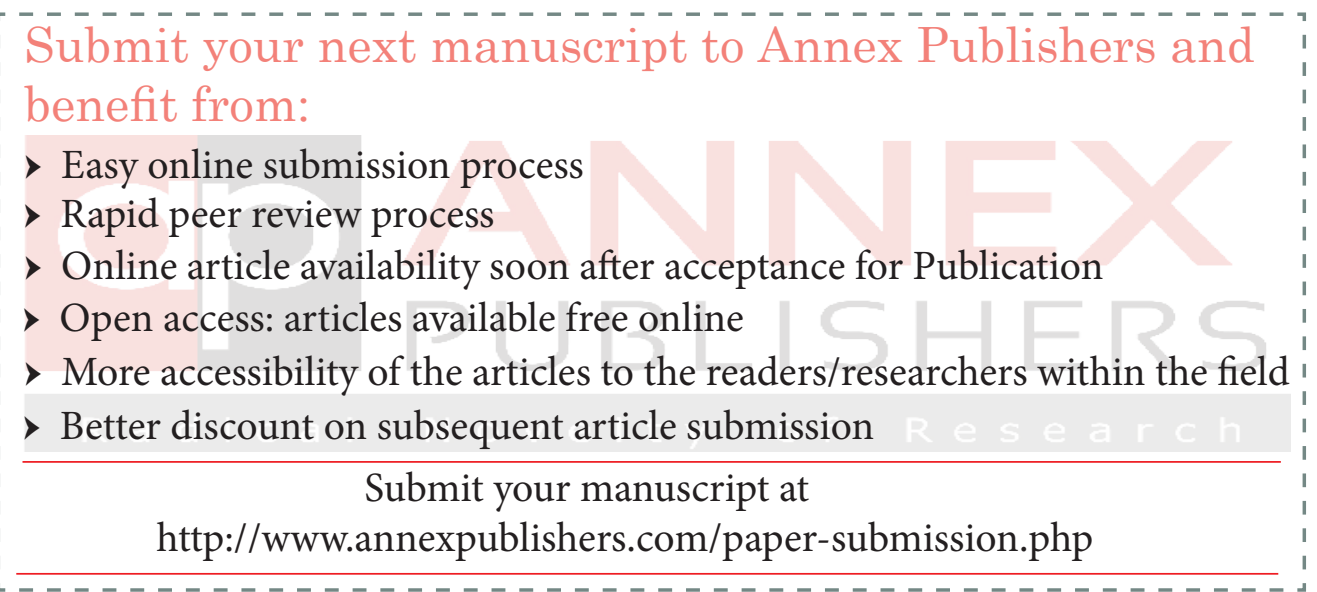

